\title{
The assistance of microwave process in sludge stabilization with sodium sulfide and sodium phosphate
}

\author{
Ching-Lung Chen ${ }^{\mathrm{a}}$, Shang-Lien $\mathrm{Lo}^{\mathrm{a}}{ }^{*}$, Pei-Te Chiueh ${ }^{\mathrm{b}}$, \\ Wen-Hui Kuan ${ }^{c}$, Ching-Hong Hsieh ${ }^{a}$ \\ ${ }^{a}$ Research Center for Environmental Pollution Prevention and Control Technology, Graduate Institute of Environmental Engineering, \\ National Taiwan University, 71, Chou-Shan Road, Taipei 106, Taiwan, ROC \\ ${ }^{\mathrm{b}}$ Department of Environmental Management, Tung Nan Institute of Technology, Taiwan, ROC \\ ${ }^{\mathrm{c}}$ Department of Environmental and Safety Engineering, Ming-Chi University of Technology, \\ No. 84, Gongjhuan Road, Taishan, Taipei Hsien 243, Taiwan, ROC
}

Received 8 August 2006; received in revised form 22 January 2007; accepted 24 January 2007

Available online 31 January 2007

\begin{abstract}
After industrial wastewater sludge passed through an acid-extraction process to reclaim most of the copper ions in it, the residue may still need to be treated by stabilization technologies. The common method for the stabilization of hazardous waste in Taiwan is by cement solidification. However, this method has the disadvantage of an increase in waste volume. In this study, it was tried to combine the advantages of sulfur anions and phosphate anions with the characteristics of microwave energy to offer a new method which can avoid the disadvantage of cement solidification. From the results, it was found that the assistance of heating in sludge stabilization with additives was effective. Huge amounts of additives were saved. Compared with the assistance of the traditional electrical-heating in sludge stabilization with additives, that of the microwave process saved much time and was more powerful. However, when the reaction time was longer, a re-leaching situation would occur. The hybrid microwave process, a procedure of leading an inert gas into the microwave process, could overcome the disadvantage of the microwave process with regard to the long reaction time. Finally, a modified hybrid microwave process which reduced the use of gas was performed and recommended.
\end{abstract}

(C) 2007 Elsevier B.V. All rights reserved.

Keywords: Copper; Microwave process; Sodium sulfide; Sodium phosphate; Stabilization; TCLP

\section{Introduction}

Industrial wastewater sludge results in a large amount of hazardous waste in Taiwan. Even though most of the copper ions in sludge are reclaimed by the acid-extraction process with sulfuric acid, the concentration of copper ions in the residue after the TCLP test may exceed $15 \mathrm{mg} / \mathrm{L}$. Hence, acid-extracted industrial sludge still needs to be stabilized. The common method for the stabilization of hazardous waste in Taiwan is cement solidification. However, this method has the disadvantage of an increase in waste volume.

\footnotetext{
* Corresponding author at: Graduate Institute of Environmental Engineering, National Taiwan University, 71 Chou-Shan Road, Taipei 106, Taiwan, ROC. Tel.: +8862 23625373; fax: +886223928830.

E-mail address: sllo@ntu.edu.tw (S.-L. Lo).
}

Sulfur anions and phosphate anions can react with heavy metal ions and then form stable compounds of low Ksp. Hence, they are used for the stabilization of hazardous waste such as contaminated soil, industrial sludge and fly ash [1-6]. Beside, microwave radiation is used in studies regarding the treatment of sewage sludge, industrial sludge, and contaminated soil because of the characteristics of microwave energy, such as uniform, quick and selective heating [7-12]. The object of this paper is to combine the advantages of sulfur anions and phosphate anions with the characteristics of microwave energy to offer a new method that can remove the sludge moisture completely, stabilize heavy metals in sludge, and avoid the disadvantage of cement solidification. Hence, it can extend the life of a landfill site and mitigate the persecution of exudation water. Besides, because microwave only takes an assistant role in this process, the energy consumption of this method is far less than that of fusion and sintering. 
In order to understand the effects of the assistance of the microwave process with additives on sludge stabilization, experiments regarding the required dosage of additives and the required reaction time, and with the assistance of traditional heating were also performed. After the above-mentioned experiments, experiments with the hybrid microwave process, a procedure of feeding an inert gas into the microwave process, were carried out in order to overcome the disadvantage of sludge stabilization with additives by the microwave process. Finally, in order to reduce the use of gas, several modified hybrid microwave processes were performed. The stabilization efficiency of each experiment was evaluated by analyzing the leachate of the sample after the TCLP test.

\section{Experimental materials and methods}

Sludge used for the experiments was the residue of industrial sludge which had gone through an acid-extraction process with sulfuric acid and from which most of the copper ions were reclaimed. In this study, two volumes of sludge extracted on different days were used, labeled A01 and A02, respectively. Sludge was dried at $105^{\circ} \mathrm{C}$ until all moisture was removed. The particle size of sludge was between 100 and 400 mesh after being crushed by a grinder. Powdery sludge had been stored in a $20 \mathrm{~L}$ bucket with a cover before it was used. A 40-g sample of sludge was placed in a circular, flat-bottomed ceramic container and the following experiments were preformed.

1. Required dosage test for sludge stabilization. The object of this experiment was to estimate the required dosages when only additives were used to stabilize the sludge at room temperature. First, $0.86,1.73,2.78$, and $3.46 \mathrm{~g}$ of sodium sulfide, and $2.74,6.08,12.2$, and $15.2 \mathrm{~g}$ of sodium phosphate were added individually to samples. Then, $50 \mathrm{~mL}$ of deionized (DI) water was added into each sample and the mixture was stirred until mixed completely.

2. Sludge stabilization with additives by the microwave process. The object of this experiment was to determine the influence of the microwave process on additives for sludge stabilization. For this process, $0.58,1.15$, and $1.73 \mathrm{~g}$ of sodium sulfide (for both A01 and A02), and 0.91, 1.82, and 2.74 g of sodium phosphate (for A01 only) were used. Each mixed sample was put into the microwave oven separately and the power was set at 600 watt (W). The reaction times were set for 3, 6, 9, and $12 \mathrm{~min}$.

3. Required reaction time test for sludge stabilization with additives. This experiment was performed in order to determine the effect of the reaction time on additives for sludge stabilization at room temperature. In this case, $1.73 \mathrm{~g}$ of sodium sulfide and $2.74 \mathrm{~g}$ of sodium phosphate were used. The mixed sample which contained $40.000 \pm 0.005 \mathrm{~g}$ of dry sludge, $50 \mathrm{~mL}$ of DI water and an additive was placed at room temperature. After $10 \mathrm{~min}, 30 \mathrm{~min}, 1 \mathrm{~h}, 2 \mathrm{~h}, 4 \mathrm{~h}, 12 \mathrm{~h}, 1$ day, 2 days, and 4 days, $5 \mathrm{~g}$ of the sample was taken to undergo the TCLP test.

4. Sludge stabilization with additives by traditional electricalheating. The microwave process could be considered a type of heating procedure. Hence, an experiment by traditional electrical-heating was performed to make a comparison. Prepared samples, which were the same as that in experiment 3 , were put into a furnace for heat treatment after it reached preset temperatures. The temperatures were set at 100, 150, 200, $250,300,350$, and $400{ }^{\circ} \mathrm{C}$, and the reaction times were 9 and $20 \mathrm{~min}$. The detailed experimental parameters in experiments 1-4 are listed in Table 1.

5. Sludge stabilization with additives by the hybrid microwave process. A re-leaching problem occurred in the experiment by microwave process. Therefore, several modified procedures were performed to correct the problem. Here, $1.15 \mathrm{~g}$ and $1.73 \mathrm{~g}$ of sodium sulfide (for both A01 and A02) and 1.82 and $2.74 \mathrm{~g}$ of sodium phosphate (for A01 only) were used in the preparation of samples. After each prepared sample was put into the microwave oven, the air in the microwave was removed by a pump and the condition in the oven was close to a vacuum. Then, $5 \mathrm{~L} / \mathrm{min}$ (LPM) of nitrogen or carbon dioxide was fed into the oven. After the pressure in the oven was returned to room atmosphere, microwave radiation was applied. The microwave power and reaction times were the same as those of experiment 2. After the microwave process, gas was fed continuously for $15 \mathrm{~min}$ to cool the sample temperature.

The above-mentioned process was an original form. Because, too much gas was used in this process, several modified processes were performed. These processes included (1) an original hybrid microwave process without a cooling period (HMP01), (2) a cooling process following a microwave process (HMP02), (3) a microwave process with a gas fed for the last $3 \mathrm{~min}$ and continuously fed for an additional $5 \mathrm{~min}$ as a cooling process (HMP03), (4) a microwave process with a gas fed for the last $3 \mathrm{~min}$ and continuously fed for an additional $10 \mathrm{~min}$ as a cooling process (HMP04), (5) a microwave process with a gas fed for the last $6 \mathrm{~min}$ and continuously fed for an additional 10 min as a cooling process (HMP05). The detailed parameters regarding these hybrid microwave processes are listed in Table 2 .

Only A01 samples were used in experiments 1, 3, and 4. In experiments 2 and 5, A01 and A02 were both used under some conditions. The DI water added in each sample of A01 was $50.0 \mathrm{~mL}$, and that of A02 was $40.0 \mathrm{~mL}$. Sodium sulfide $\left(\mathrm{Na}_{2} \mathrm{~S} \cdot 9 \mathrm{H}_{2} \mathrm{O}\right)$ and sodium phosphate $\left(\mathrm{Na}_{3} \mathrm{PO}_{4} \cdot 12 \mathrm{H}_{2} \mathrm{O}\right)$ used in experiments were both of analysis grade.

The potential maximum power of the industrial microwave oven employed in this study was $1600 \mathrm{~W}$. The simplified structure of the microwave oven is shown in Fig. 1. The valve on the top of the oven is to let the gas out. The valve on the right is for insertion of the gas and is connected to a float flow meter to control the flow rate of gas. The one on the left is connected to a vacuum pump which can provide a near vacuum condition in the oven. A container filled with the prepared sample was placed in the center of a flat tray at the bottom of the oven.

After samples had passed through the above-mentioned experiments, $5 \mathrm{~g}$ of each sample was subjected to the TCLP test. The extractate used in this paper was extraction fluid \#2, 
Operational parameters

\begin{tabular}{|c|c|c|c|c|c|c|c|}
\hline Experiment & $\begin{array}{l}\text { Sludge } / \mathrm{H}_{2} \mathrm{O} \\
(\mathrm{g} / \mathrm{mL})\end{array}$ & Additive & Dosage (g/40g-dried sludge) & Gas & $\begin{array}{l}\text { Flow rate } \\
\text { (LPM) }\end{array}$ & Heating type & Reaction time \\
\hline No treatment & $5 \mathrm{~g}$ & - & - & - & - & - & - \\
\hline Microwave process for sludge stabilization & $40 / 50$ & - & - & - & - & $\begin{array}{l}\text { Microwave } \\
\text { heating } \\
(600 \mathrm{~W})\end{array}$ & $3,6,9,12 \mathrm{~min}$ \\
\hline Required dosage test for sludge stabilization & $40 / 50$ & $\begin{array}{l}\mathrm{Na}_{2} \mathrm{~S} \\
\mathrm{Na}_{3} \mathrm{PO}_{4}\end{array}$ & $\begin{array}{l}0.86,1.73,2.78,3.46 \\
2.74,6.08,12.2,15.2\end{array}$ & - & - & - & - \\
\hline Sludge stabilization with additives by the microwave process & $40 / 50$ & $\begin{array}{l}\mathrm{Na}_{2} \mathrm{~S} \\
\mathrm{Na}_{3} \mathrm{PO}_{4}\end{array}$ & $\begin{array}{l}0.58,1.15,1.73 \\
0.91,1.82,2.74 \\
(0.002,0.005,0.007 \mathrm{~mol})\end{array}$ & - & - & $\begin{array}{l}\text { Microwave } \\
\text { heating } \\
(600 \mathrm{~W})\end{array}$ & $3,6,9,12 \mathrm{~min}$ \\
\hline Required reaction time test for sludge stabilization with additives & $40 / 50$ & $\begin{array}{l}\mathrm{Na}_{2} \mathrm{~S} \\
\mathrm{Na}_{3} \mathrm{PO}_{4}\end{array}$ & $\begin{array}{l}1.73 \\
2.74 \\
(0.007 \mathrm{~mol})\end{array}$ & - & - & - & $\begin{array}{l}10,30 \mathrm{~min}, 1,2,4 \text {, } \\
12 \mathrm{~h}, 1,2,4 \text { day }\end{array}$ \\
\hline Sludge stabilization with additives by a heating process & $40 / 50$ & $\begin{array}{l}\mathrm{Na}_{2} \mathrm{~S} \\
\mathrm{Na}_{3} \mathrm{PO}_{4}\end{array}$ & $\begin{array}{l}1.73 \\
2.74 \\
(0.007 \mathrm{~mol})\end{array}$ & - & - & $\begin{array}{l}\text { Furnace }(100, \\
150,200,250, \\
300,350, \\
\left.400^{\circ} \mathrm{C}\right)\end{array}$ & 9,20 \\
\hline
\end{tabular}

Table 2

Operational parameters II—hybrid microwave processes

\begin{tabular}{|c|c|c|c|c|c|c|c|c|}
\hline Experiment & $\begin{array}{l}\text { Sludge } / \mathrm{H}_{2} \mathrm{O} \\
(\mathrm{g} / \mathrm{mL})\end{array}$ & Additive & Dosage (g/40g-dried sludge) & Gas & $\begin{array}{l}\text { Flow rate } \\
\text { (LPM) }\end{array}$ & $\begin{array}{l}\text { Reaction } \\
\text { time (min) }\end{array}$ & Gas leading Period & Cooling Period \\
\hline Original form & $\begin{array}{l}\text { A01: } 40 / 50 \\
\text { A02: } 40 / 40\end{array}$ & $\begin{array}{l}\mathrm{Na}_{2} \mathrm{~S} \\
\mathrm{Na}_{3} \mathrm{PO}_{4}\end{array}$ & $\begin{array}{l}1.15,1.73 \\
1.82,2.74(0.005,0.007 \mathrm{~mol})\end{array}$ & $\begin{array}{l}\mathrm{CO}_{2} \\
\mathrm{~N}_{2}\end{array}$ & 5 & $3,6,9,12$ & All & All \\
\hline HMP01 & A02: 40/40 & $\mathrm{Na}_{2} \mathrm{~S}$ & $1.15,1.73(0.005,0.007 \mathrm{~mol})$ & $\mathrm{N}_{2}$ & 5 & $3,6,9,12$ & All & - \\
\hline HMP02 & A02: $40 / 40$ & $\mathrm{Na}_{2} \mathrm{~S}$ & $1.15,1.73(0.005,0.007 \mathrm{~mol})$ & $\mathrm{N}_{2}$ & 5 & $3,6,9,12$ & - & All \\
\hline HMP03 & A02: 40/40 & $\mathrm{Na}_{2} \mathrm{~S}$ & $1.15,1.73(0.005,0.007 \mathrm{~mol})$ & $\mathrm{N}_{2}$ & 5 & $3,6,9,12$ & The last 3 mins & 5 mins \\
\hline HMP04 & A02: $40 / 40$ & $\mathrm{Na}_{2} \mathrm{~S}$ & $1.15,1.73(0.005,0.007 \mathrm{~mol})$ & $\mathrm{N}_{2}$ & 5 & 12 & The last 3 mins & $10 \mathrm{mins}$ \\
\hline HMP05 & A02: 40/40 & $\mathrm{Na}_{2} \mathrm{~S}$ & $1.15,1.73(0.005,0.007 \mathrm{~mol})$ & $\mathrm{N}_{2}$ & 5 & 12 & The last 6 mins & $10 \mathrm{mins}$ \\
\hline Final form & A02: $40 / 40$ & $\mathrm{Na}_{2} \mathrm{~S}$ & $1.15,1.73(0.005,0.007 \mathrm{~mol})$ & $\mathrm{N}_{2}$ & 5 & $3,6,9,12$ & After the 6 mins of the reaction time & 10 mins (when gas was led) \\
\hline
\end{tabular}




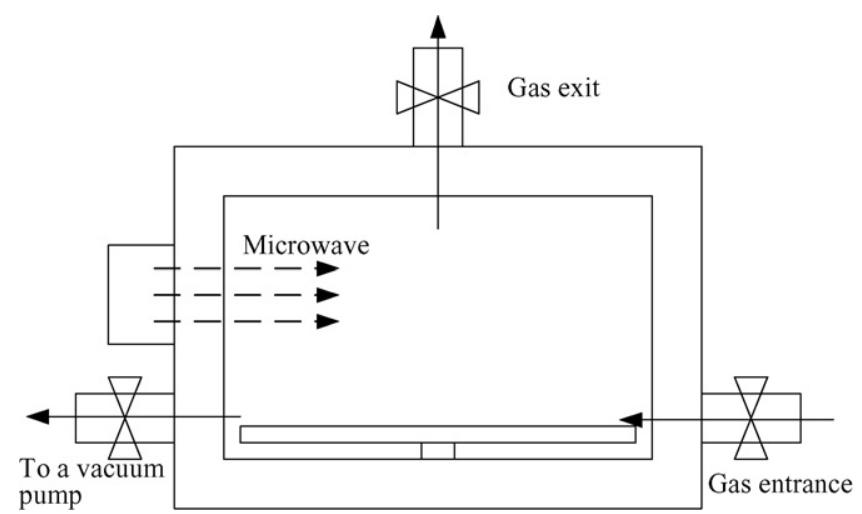

Fig. 1. The simplified structure of the microwave oven.

1.0 $\mathrm{M}$ acetic acid solution with a $\mathrm{pH}$ value of $2.88 \pm 0.05$, in order to provide a severe condition. The ratio of liquid to solids was 20:1 and the rotation frequency was 30 revolutions per minute (RPM). After $18 \pm 2 \mathrm{~h}$ for the extraction, the leachate was filtered and the filtrate $\mathrm{pH}$ was adjusted to below 2. The filtrate was instantly analyzed with ICP (Jobin Yvon JY24) to prevent the formation of colloid and sediment. The resulting dried sludge after the TCLP test was used for the basis in all experiments.

\section{Results and discussions}

\subsection{The basic description of sludge}

The element compositions of the sludge are listed in Table 3. About $0.2 \mathrm{~g}$ dried sludge was recorded and subjected to microwave-assisted digestion. Then, the digestion solution was filtered, diluted and analyzed with ICP. The results show that the contents of alkali and alkaline earth metals were low except for calcium. The reason might be that calcium ions and sulfate

Table 3

Element compositions

\begin{tabular}{lcc}
\hline Element & \multicolumn{2}{l}{ Concentration $(\mathrm{mg} / \mathrm{g})$} \\
\cline { 2 - 3 } & $\mathrm{A} 01$ & $\mathrm{~A} 02$ \\
\hline $\mathrm{Ag}$ & 0.08 & - \\
$\mathrm{Al}$ & 17.3 & 3.30 \\
$\mathrm{Ba}$ & 0.69 & - \\
$\mathrm{Ca}$ & 134 & 70.8 \\
$\mathrm{Cd}$ & $-{ }^{\mathrm{a}}$ & - \\
$\mathrm{Co}$ & 0.25 & - \\
$\mathrm{Cr}$ & 0.24 & 1.37 \\
$\mathrm{Cn}$ & 13.1 & 9.08 \\
$\mathrm{Fe}$ & 44.2 & 10.4 \\
$\mathrm{~K}$ & 1.79 & 1.22 \\
$\mathrm{Mg}$ & 1.02 & 1.13 \\
$\mathrm{Mn}$ & 0.25 & - \\
$\mathrm{Na}$ & 11.6 & 2.17 \\
$\mathrm{Ni}$ & 4.88 & - \\
$\mathrm{Pb}$ & 6.26 & 0.01 \\
$\mathrm{Si}{ }^{\mathrm{b}}$ & 87.2 & 0.73 \\
$\mathrm{Zn}$ & 0.74 & \\
\hline
\end{tabular}

a The concentration was lower than $0.05 \mathrm{mg} / \mathrm{g}$.

b Silicon in A02 was not analyzed. anions which came from the sulfuric acid in the extraction process formed the low dissoluble compound, $\mathrm{CaSO}_{4}$. The same phenomenon occurred for lead in A01. However, the lead content in A02 was very low. This dissimilarity may result from the natural difference between A01 and A02. Copper contents in A01 and A02 were 13.1 and $9.08 \mathrm{mg} / \mathrm{g}$, respectively and were the highest regarding their heavy metal content. Though copper contents were about one percent of the dried sludge weight, leaching concentrations of copper ions were 90.2 and $58.7 \mathrm{mg} / \mathrm{L}$, respectively after the TCLP test.

\subsection{The effects of additives on stabilization}

Because the content and leaching concentration of copper in $\mathrm{A} 01$ was higher than that in A02, essential experiments were performed with A01. Various dosages of sodium sulfide and sodium phosphate were used to decrease the concentration of copper ions to below $15 \mathrm{mg} / \mathrm{L}$ and to estimate the required amounts of additives for sludge stabilization at room temperature. Fig. 2 shows the relationship between the leaching concentration of copper ions and the additive dosage. The concentration decreased with the increase of the dosage. From the equations, the required amounts of sodium sulfide and sodium phosphate for the concentration below $15 \mathrm{mg} / \mathrm{L}$ were $2.26 \mathrm{~g} / 40 \mathrm{~g}$-dried sludge and $16.0 \mathrm{~g} / 40 \mathrm{~g}$-dried sludge, respectively. From the following formulas, it can be found that the amount of copper ions caught by phosphate anions is 1.5 times that caught by sulfide anions of the same molar amount:

$$
\begin{aligned}
& 2 \mathrm{PO}_{4}{ }^{3-}+3 \mathrm{Cu}^{2+} \rightarrow \mathrm{Cu}_{3}\left(\mathrm{PO}_{4}\right)_{2} \\
& \mathrm{~S}^{2-}+\mathrm{Cu}^{2+} \rightarrow \mathrm{CuS}
\end{aligned}
$$

Hence, the theoretical effect of sodium phosphate should be better than that of sodium sulfide. However, the actual dosage of the former for $40 \mathrm{~g}$ sludge was $16.0 \mathrm{~g}\left(0.042 \mathrm{~mol} \mathrm{PO}_{4}{ }^{3-}\right)$, which was higher than that of the latter $\left(2.26 \mathrm{~g}, 0.009 \mathrm{~mol} \mathrm{~S}^{2-}\right)$. Hence, sodium sulfide should be a better additive for stabilization of this sludge.

Fig. 3 shows the influence of the reaction time on additives at room temperature for sludge stabilization. The dosages of the sodium sulfide and sodium phosphate were $1.73 \mathrm{~g} / 40 \mathrm{~g}$ -

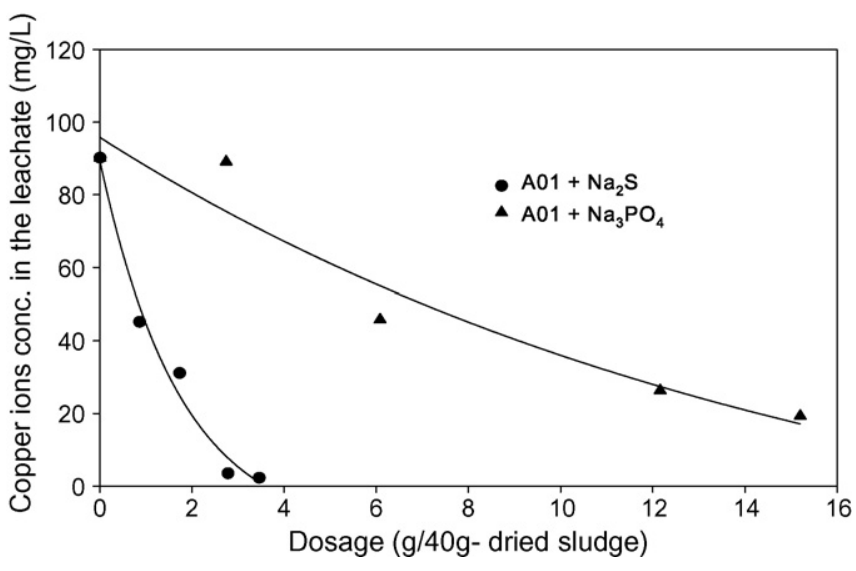

Fig. 2. Effects of additive dosages on stabilization of A01. 


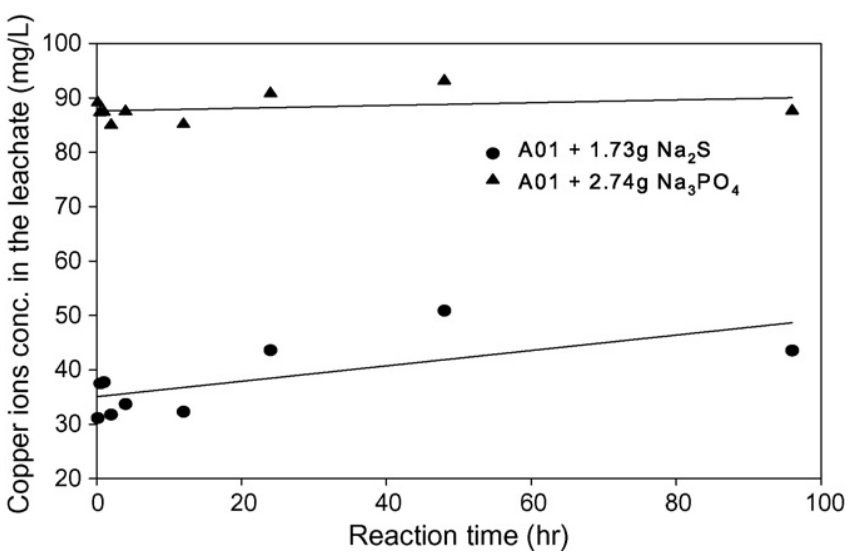

Fig. 3. The influence of the reaction time on additives at room temperature for stabilization of A01.

dried sludge and $2.74 \mathrm{~g} / 40 \mathrm{~g}$-dried sludge which both equaled $0.007 \mathrm{~mol}$ anions $/ 40 \mathrm{~g}$-dried sludge. The results indicate that sodium phosphate, at this dosage, was almost ineffective even when the reaction time was 4 days. The concentration of copper ions from the sludge with sodium sulfide was about $40 \mathrm{mg} / \mathrm{L}$ irrespective of the reaction time. Because the concentration of copper ions did not decrease with the increase in reaction time, it can be assumed that the required time for the reactions of sludge and additives is less than $10 \mathrm{~min}$.

Fig. 4 shows the heating effect on additives for sludge stabilization. The concentration of copper ions had a decreasing tendency when the temperature increased. Moreover, the effects of additives on sludge stabilization increased with the increase of the reaction time. The lowest concentrations of copper ions from the sludge with additives were found when the reaction time was $20 \mathrm{~min}$ and the temperature of the furnace was $400{ }^{\circ} \mathrm{C}$. The leaching concentrations of sludge with sodium sulfide and sodium phosphate were 8.09 and $16.3 \mathrm{mg} / \mathrm{L}$, respectively at the anion concentration of $0.007 \mathrm{~mol} / 40 \mathrm{~g}$-dried sludge. These results show that heat can reduce efficiently the required dosages of sodium sulfide and sodium phosphate when they are used to stabilize the copper ions in sludge. Hence, it could be conjectured that heat improves the stabilization efficiency of additives.

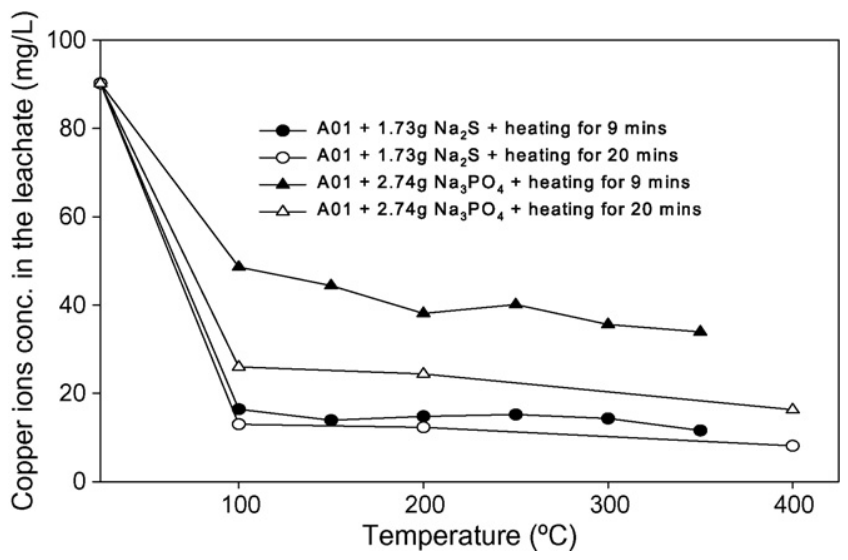

Fig. 4. The heating effect on additives for stabilization of A01.

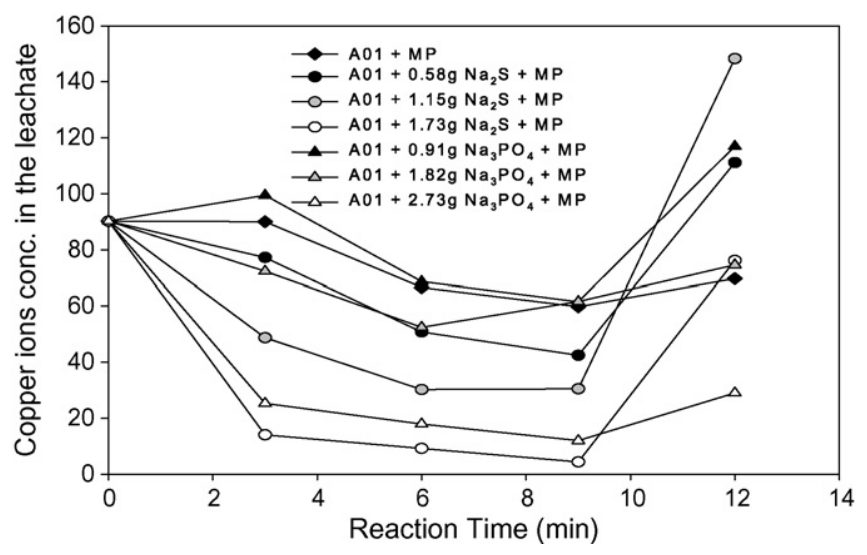

Fig. 5. The effect of the microwave process on additives for stabilization of A01. MP: microwave process.

\subsection{The assistance of the microwave process in sludge stabilization with additives}

Fig. 5 shows the effect of the microwave process on additives for the stabilization of sludge A01. Where the reaction time was below $9 \mathrm{~min}$, the results show that the concentration of copper ions was reduced with increases of the reaction time and of the additive dosage. No matter what the dosage was, the effect of sodium sulfide on the stabilization was better than that of sodium phosphate. When the anion concentration of the additive was $0.007 \mathrm{~mol} / 40 \mathrm{~g}$-dried sludge, the lowest leaching concentrations of the sludge with sodium sulfide and sodium phosphate were 4.35 and $12.0 \mathrm{mg} / \mathrm{L}$, respectively, which were both lower than the standard of $15 \mathrm{mg} / \mathrm{L}$. Compared with the results of experiments assisted by traditional heating, those assisted by the microwave process showed better effect on sludge stabilization. Moreover, the reaction time of the microwave process was shorter than that of traditional heating. Besides, the experiments assisted by the microwave process were performed before those by traditional heating, and the purpose of the latter was to understand whether heating would improve the effects of additives on sludge stabilization or not. In Section 3.2, the results show that heating certainly enhanced the stabilization ability of additives, which resulted in that only small amounts of additives were used to reduce the leaching concentrations from 90.2 to $8.09 \mathrm{mg} / \mathrm{L}$ for $\mathrm{A} 01$ with sodium sulfide and $16.3 \mathrm{mg} / \mathrm{L}$ for A01 with sodium phosphate, respectively (Fig. 4). Moreover, the results of experiments assisted by the microwave process show that this process was more powerful than traditional heating in the aspect of assisting additives in sludge stabilization. Not only did the leaching concentration decrease more, but the reaction time also decreased from 20 to $9 \mathrm{~min}$. Microwave radiation is absorbed directly by sludge and then transformed into heat within the sludge [13]. However, traditional heating transmits heat to sludge by conduction and convection. From these two ways of transmission, it is clear why the effect of additives assisted by the microwave process on sludge stabilization is better than that by traditional heating.

When the reaction time was $12 \mathrm{~min}$, the leaching concentrations of copper ions from the sludge with additives increased 


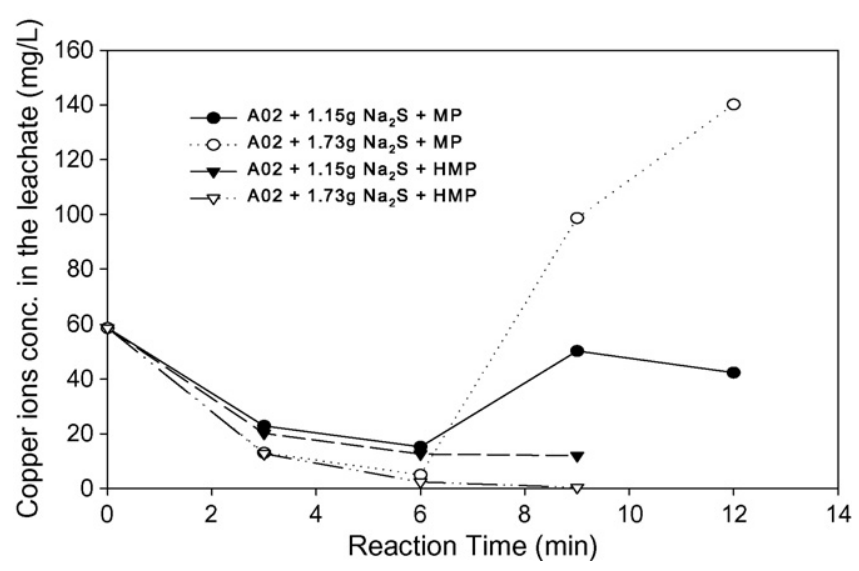

Fig. 6. Effects of the microwave process and the hybrid microwave process of nitrogen on sodium sulfide for stabilization of A02. MP: microwave process; HMP: hybrid microwave process.

suddenly, no matter what the dosage was. Fig. 6 shows that the same situation occurred when A02 was used. Moreover, the occurrence time was advanced to $9 \mathrm{~min}$. After the moisture of sludge was removed, this occurred at almost $6 \mathrm{~min}$, the temperature of sludge increasing faster. In the case of $\mathrm{A} 01$, the temperatures of those samples were more than $450{ }^{\circ} \mathrm{C}$ when the reaction time was $12 \mathrm{~min}$. Furthermore, when these samples were moved to a ventilated system to cool down, they smoldered continuously for some time. The study of Dunn and Muzenda [14] shows that when the temperature is higher than $474{ }^{\circ} \mathrm{C}$, copper sulfide $(\mathrm{CuS})$ begins to be transformed to other substances such as copper (I) oxide $\left(\mathrm{Cu}_{2} \mathrm{O}\right)$ and copper sulfate $\left(\mathrm{CuSO}_{4}\right)$ which are not as stable as copper sulfide. It is possible that the temperature of sludge was higher than $474^{\circ} \mathrm{C}$ during the smoldering period, which resulted in the formation of unstable compounds. These compounds then caused the increase of the leaching concentration of copper ions from the sludge after the TCLP test. However, the question arises why the presence of releaching in A02 was earlier than that in A01. The definite reason is still not clear, but it may be related to the amount of organic compounds in A02 (about $30 \mathrm{wt} \%$ ) being higher than that in A01 (about $15 \mathrm{wt} \%$ ). Higher amounts of organic compounds may extend the smoldering period. Another possible factor is that the moisture in A02 was less than that in A01. Hence, the quickened heating, which follows the disappearance of moisture in sludge, was earlier in A02 than in A01. Copper phosphate is also known to be decomposed at high temperature. However, the detail mechanism is not as clear as that of copper sulfide.

\subsection{The assistance of the hybrid microwave process in sludge stabilization with additives}

The transformation mechanism of copper sulfide to other compounds is oxidation [14]. Hence, feeding an inert gas in the microwave process, which is called the hybrid microwave process, was considered in order to avoid the smoldering of the sludge and to cool down its temperature. The similar process was used in the study of Hsieh et al. [15]. Nitrogen and carbon dioxide were selected for A01 because they are inert gases. Figs. 7 and 8 show the results of hybrid microwave processes of nitrogen and

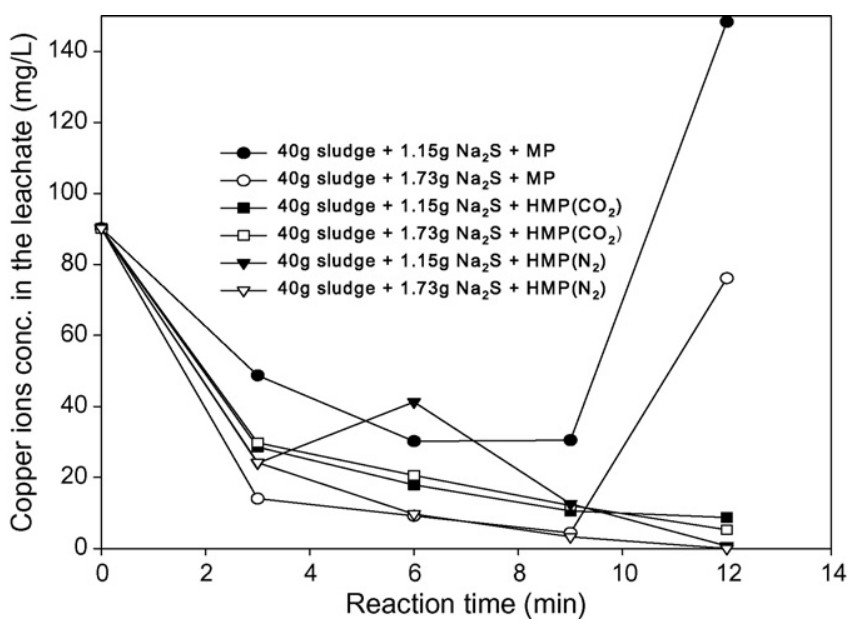

Fig. 7. Effects of hybrid microwave processes of nitrogen and carbon dioxide on sodium sulfide for stabilization of A01. MP: microwave process; HMP: hybrid microwave process.

carbon dioxide for the stabilization of A01. The results show that the hybrid microwave process solved the re-leaching problem of copper ions from A01 with additives for $12 \mathrm{~min}$ after the microwave process. The sudden peaks were not again present at the reaction time. Furthermore, when the anion concentration of the additive was $0.005 \mathrm{~mol}\left(\mathrm{Na}_{2} \mathrm{~S}: 1.15 \mathrm{~g} ; \mathrm{Na}_{3} \mathrm{PO}_{4}: 1.82 \mathrm{~g}\right) / 40 \mathrm{~g}$ dried sludge, the effect of the hybrid microwave process on sludge stabilization with additives was better than that of the microwave process. In the sodium sulfide system, the lowest leaching concentration of copper ions from the sludge treated by the microwave process was $30.2 \mathrm{mg} / \mathrm{L}$. When the sludge was treated by the hybrid microwave processes of nitrogen and carbon dioxide, the lowest concentrations were 0.68 and $8.70 \mathrm{mg} / \mathrm{L}$, respectively. In the sodium phosphate system, the lowest concentration decreased from 52.5 to 34.4 and then to $30.4 \mathrm{mg} / \mathrm{L}$, respectively. From these results, it was found that the hybrid microwave process could not only control the sludge temperature to avoid the re-leaching, but could also improve the effects of additives with the microwave process on sludge stabilization.

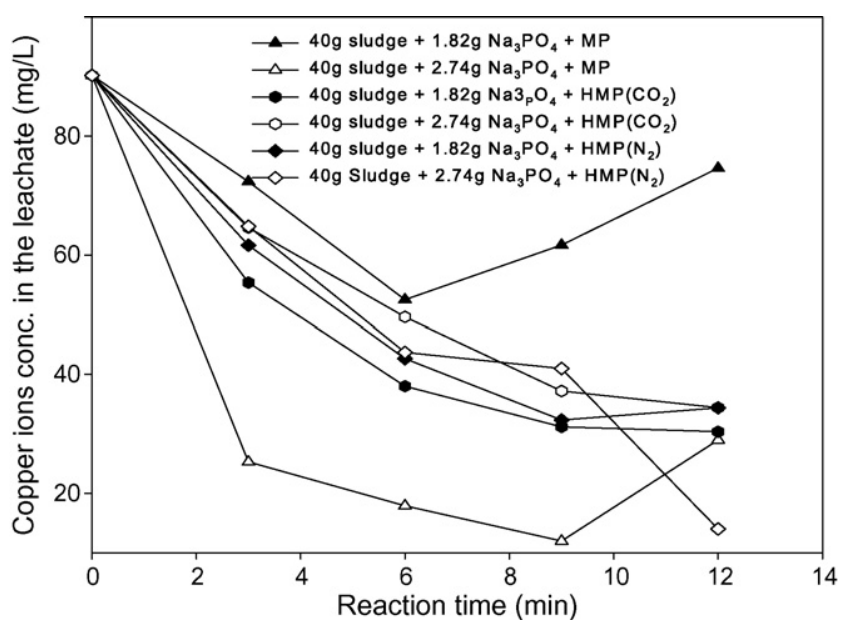

Fig. 8. Effects of hybrid microwave processes of nitrogen and carbon dioxide on sodium phosphate for stabilization of A01. MP: microwave process; HMP: hybrid microwave process. 


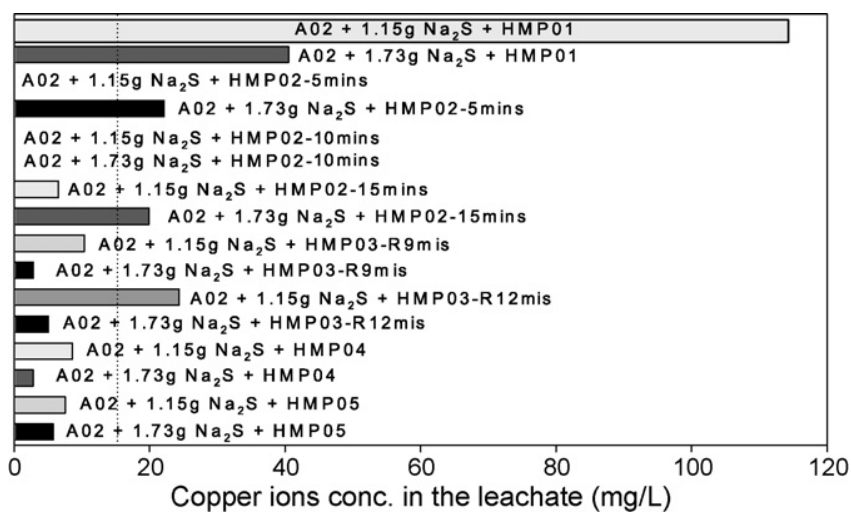

Fig. 9. Effects of modified hybrid microwave processes of nitrogen on sodium phosphate for stabilization of A02. HMP01: an original hybrid microwave process without a cooling period; HMP02: a cooling process behind a microwave process; HMP03: a microwave process with a gas led for the last $3 \mathrm{~min}$ and a cooling process of 5 min following it; HMP04: a microwave process with a gas led for the last $3 \mathrm{~min}$ and a cooling process of $10 \mathrm{~min}$ following it; HMP05: a microwave process with a gas led for the last $6 \mathrm{~min}$ and a cooling process of 10 min following it.

When the anion concentration of the $\mathrm{Na}_{2} \mathrm{~S}$ was $0.007 \mathrm{~mol}$ $(1.73 \mathrm{~g}) / 40 \mathrm{~g}$-dried sludge, the lowest leaching concentrations of the sludge treated with the hybrid microwave processes of nitrogen and carbon dioxide in the sodium sulfide system were $5.26 \mathrm{mg} / \mathrm{L}$ and under the detection limit. The results showed that the effect of the hybrid microwave process on A01 stabilization did not rise with the dosage increase of the additive. Moreover, the leaching concentration of the sludge treated with the hybrid microwave process might be higher than that of the microwave process. From figures, it was found that the leaching concentrations of copper ions from the sludge treated by the hybrid microwave processes with low dosage of additives were close to those with high dosage. Furthermore, they were almost between the leaching concentrations from the sludge with the dosages of additives of 0.005 and $0.007 \mathrm{~mol} / 40 \mathrm{~g}$-dried sludge after the microwave process when the reaction time was below 9 min. Besides, these results show that the effect of the hybrid microwave process on assisting sodium phosphate in sludge stabilization was disappointing. Hence, sodium phosphate may not be a suitable additive for this process.

Fig. 6 also shows the results of the hybrid microwave process of nitrogen for the stabilization of A02. The results again confirm the advantage of the hybrid microwave process of nitrogen. Compared with the results of A01 by the hybrid microwave process, those of A02 show a clear decreasing tendency with the increase in the dosage of sodium sulfide. The difference might come from the natural dissimilarity between them. In our rough experiment (data not shown), the effect of the hybrid microwave process on sludge stabilization was possibly related to the amount of organic compounds in sludge. Of course, this supposition needs to be confirmed accurately.

Though the hybrid microwave process was effective, too much gas was used in this process. Hence, some modified hybrid microwave processes were performed. Fig. 9 shows the results of $\mathrm{A} 02$ by these modified processes. It was found that if the cooling process was removed (HMP01), the effect of the hybrid microwave process on assisting sodium sulfide in sludge stabilization was bad. This situation indicates that a cooling process to restrain sludge smoldering is necessary. However, re-leaching might still occur if nitrogen is fed only after the microwave process and not during it (HMP02), which means that the sludge temperature might be high enough to force copper sulfide to transform. Hence, the feeding of nitrogen both in and after the microwave process had to be considered.

Fig. 9 also shows that the re-leaching disappeared for the reaction time of 9 min using the microwave process with nitrogen fed for the last $3 \mathrm{~min}$ and a cooling process of $5 \mathrm{~min}$ following it (HMP03). However, when the reaction time increased to $12 \mathrm{~min}$, the occurrence of re-leaching could not be limited completely. Therefore, experiments for the reaction time of $12 \mathrm{~min}$ using the microwave process with nitrogen fed for the last $3 \mathrm{~min}$ and a cooling process of $10 \mathrm{~min}$ (HMP04) and also with nitrogen fed for the last $6 \mathrm{~min}$ and a cooling process of $10 \mathrm{~min}$ (HMP05) were performed. The results both show that these two modified hybrid microwave processes could effectively assist sodium sulfide in sludge stabilization and substantially reduce the use of nitrogen in comparison with the original hybrid microwave process. The results of HMP04 were better than those of HMP05, and the use of nitrogen in the former was less than that of the latter. However, the leaching concentrations of repetitions of HMP04 were sometimes still higher than $15 \mathrm{mg} / \mathrm{L}$. Hence, HMP05 was preferred. Besides, from the results of HMP03, HMP04, and HMP05, it could be considered that the suitable timing to start feeding nitrogen was at the reaction time of $6 \mathrm{~min}$. Also, because this timing was close to the time that the sludge moisture was removed completely, the variation of the sludge temperature, which can be measured roughly with an IR thermal detector, could be an index too. Hence, the final modified hybrid microwave process was to feed nitrogen into a microwave process when the reaction time was more than $6 \mathrm{~min}$ and then to perform a cooling process of 10 min with nitrogen. Fig. 10 shows the results of this process. From the leaching results and their standard deviations, the final modified hybrid microwave process could be considered to be an effective method for the stabilization of sludge containing copper ions.

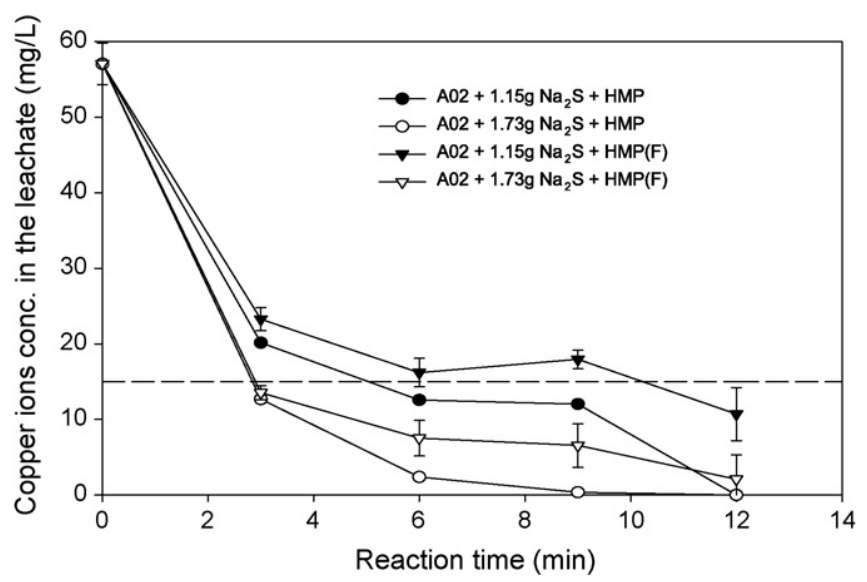

Fig. 10. Effects of the final modified hybrid process of nitrogen on sodium phosphate for stabilization of A02. MP: microwave process; HMP: hybrid microwave process; $\mathrm{HMP}(\mathrm{F})$ : final modified hybrid process. 


\section{Conclusions}

The effects of sodium sulfide and sodium phosphate on sludge stabilization were immediate, and rose with the increase of temperature. Compared with the assistance of traditional heating in sludge stabilization with additives, the assistance of the microwave process was effective because of the characteristics and the manner of transmission of microwave heating. Moreover, the assistance of the microwave process saved time and was more powerful. However, when the reaction time was longer, the leaching concentration of copper ions from sludge with additives after the microwave process increased suddenly because the stable compounds such as copper sulfide and copper phosphate were decomposed at the high temperature. The hybrid microwave process could overcome the disadvantage of the microwave process for long reaction times. A modified hybrid microwave process was also performed, and this process could limit the re-leaching for longer reaction time and reduce the use of nitrogen. The role that the inert gas such as nitrogen played in the hybrid microwave process is not clear, and it is a topic for future study.

\section{Acknowledgements}

This work was financially supported by the Ministry of Economic Affairs, R.O.C. in the framework of the projects 95EC-17-A-10-S1-0007.

\section{References}

[1] S.L. Lin, J.S. Lai, E.S.K. Chian, Modificatios of sulfur polymer cement (SPC) stabilization and solidification (S/S) process, Waste Manage. 15 (5/6) (1995) 441-447.
[2] H. Katsuura, T. Inoue, M. Hiraoka, S. Sakai, Full-scale plant study on fly ash treatment by the acid extraction process, Waste Manage. 16 (5/6) (1996) 491-499.

[3] R. Derie, A new way to stabilize fly ash from municipal incinerators, Waste Manage. 16 (8) (1996) 711-716.

[4] T.T. Eighmy, B.S. Crannell, J.E. Krzanowski, L.G. Butler, F.K. Cartledge, E.F. Emery, J.D. Eusden Jr., E.L. Shaw, C.A. Francis, Characterization and phosphate stabilization of dusts from the vitrification of MSW combustion residues, Waste Manage. 18 (1998) 513-524.

[5] A. Nzihou, P. Sharrock, Calcium phosphate stabilization of fly ash with chloride extraction, Waste Manage. 22 (2002) 235-239.

[6] B. Bournonville, A. Nzihou, P. Sharrock, G. Depelsenaire, Stabilisation of heavy metal containing dusts by reaction with phosphoric acid: study of the reactivity of fly ash, J. Hazard. Mater. 116 (1/2) (2004) 6574.

[7] H.S. Tai, C.J.G. Jou, Immobilization of chromium-contaminated soil by means of microwave energy, J. Hazard. Mater. 65 (1999) 267275.

[8] J.T. Bohlmann, C.M. Lorth, A. Drews, R. Buchholz, Microwave high pressure thermo-chemical conversion of sewage sludge as an alternative to incineration, Chem. Eng. Technol. 21 (1999) 404-409.

[9] Q. Gan, A case study of microwave processing of metal hydroxide sediment sludge from printed circuit board manufacturing wash water, Waste Manage. 20 (2001) 695-701.

[10] H.S. Ku, E. Siores, A. Taube, J.A.R. Ball, Productivity improvement through the use of industrial microwave technologies, Comput. Ind. Eng. 42 (2002) 281-290.

[11] J.A. Menéndez, M. Inguanzo, J.J. Pis, Microwave-induced pyrolysis of sewage sludge, Water Res. 36 (2002) 3261-3264.

[12] C.L. Chen, S.L. Lo, W.H. Kuan, C.H. Hsieh, Stabilization of Cu in acidextracted industrial sludge using a microwave process, J. Hazard. Mater. 123 (1-3) (2005) 256-261.

[13] P. Lidström, J. Tierney, B. Wathey, J. Westman, Microwave assisted organic synthesis-a review, Tetrahedron 57 (2001) 9225-9283.

[14] J.G. Dunn, C. Muzenda, Thermal oxidation of covellite (CuS), Thermochim. Acta $369(1 / 2)(2001) 117-123$.

[15] C.H. Hsieh, S.L. Lo, P.T. Chiueh, W.H. Kuan, C.L. Chen, Microwave enhanced stabilization of heavy metal sludge, J. Hazard. Mater. B139 (2007) 160-166. 